\title{
An Examination Of Core Self Evaluations (CSE) In An Academic Setting: Does CSE Generalize To Students?
}

Willard G. Broucek, (E-mail: broucekw@ northern.edu), Northern State University

\begin{abstract}
This paper examines the construct of Core Self Evaluation (Judge, Erez, Bono, and Thoresen, 2003) and extends its applicability to the academic setting. The relationship between CSE scores, Student Satisfaction, Grade Point Average, and Life Satisfaction, is discussed.
\end{abstract}

\section{INTRODUCTION}

\section{LITERATURE REVIEW}

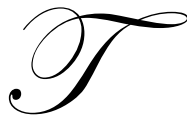

he concept of Core Self Evaluations (CSE's) refers to fundamental, subconscious conclusions that individuals reach about themselves, other people, and the world. It was proposed by Judge, Locke, and Durham (1997) as a dispositional source of job satisfaction and, subsequently, of life satisfaction as well (Judge, Locke, Durham, and Kluger, (1998).

According to Judge et al. (1997), core self evaluations is a broad, higher-order trait comprised of four wellknown personality traits. These constituent traits are: self-esteem, the overall value that one places upon oneself (Harter, 1990); generalized self efficacy, an evaluation of one's performance capabilities across situations (Locke, McClear, \& Knight, (1996); emotional stability v. neuroticism, the tendency to experience negative emotions (Costa $\&$ McCrae, 1992); and locus of control, beliefs about the causal control of the events in one's life (Rotter, 1966).

Although these four traits are among the more prominent variables studied in psychology, Judge and Bono (2001) noted that typically the traits are studied in isolation not in combination. Judge and his colleagues, on the other hand, argue that the four traits are indicators of a higher-order latent concept as indicated by the fact that they load on as single factor (Erez \& Judge, 2001; Judge, Bono \& Locke, 2000; Judge, Erez, \& Bono, 1998; Judge et al., 1998). As a broad latent trait, core self evaluations is the common source of the four traits that causes them to be related.

An individual who scores high on core self evaluations is said to be well adjusted, positive, self-confident, and efficacious, and possesses a belief in his/her agency. In short, general, positive self-regard is at the heart of the four constituent traits. Each of the four traits is seen as a manifestation or indicator of the inner self-concept. Core self evaluations are thus a latent commonality underlying the four traits.

Initially, the measurement of core self evaluations was indirect. The mega-trait of core self evaluation emerged only when the four constituent traits were measured and then factor analyzed. This indirect approach raised questions regarding the validity of core self evaluations as a construct and did not address the question of whether the mega-trait was a latent or an aggregate construct (Judge, Erez, Bono, \& Thoresen, 2003). Latent constructs exist at a deeper level than their indicators and causally influence them as opposed to aggregate constructs which are comprised of items that may or may not be related.

On a more practical level, Judge et al. (2003) also noted that indirect measurement of CSE's was somewhat lengthy requiring use of four separate scales comprised of 38 items. Finally, they also noted problems with the 
empirical validity of the indirect approach, i.e., the four constituent traits display slightly differential relations with criterion variables (Judge \& Bono, 2001b).

To obviate these concerns Judge et al. (2003) presented the results of a series of studies in which they provided a direct measure of core self evaluations termed the Core Self-Evaluations Scale (CSES). This scale, comprised of 12 items, was demonstrated to be reliable and had a unitary factor structure, validity equal to that of an optimal weighting of its four core traits, and incremental validity beyond the five factor model. As well, scores on the CSES significantly correlated with job satisfaction, life satisfaction, and job performance.

Given that Judge and his colleagues have successfully linked positive core self evaluations with job and life satisfaction as well as job performance, it seems reasonable to extend the CSE concept to other settings and populations. Specifically, if people who consider themselves worthy and able to cope with life's exigencies bring a positive frame to the events and situations they encounter at work and in life then if follows that students who have positive core self evaluations should also bring a positive frame to both the school context and life. Therefore, this study attempted to examine the extent to which both the concept and the measure of core self evaluations could be extended to university students in an academic setting.

If CSE is generalizeable to university students in an academic setting then the following hypotheses should be supported:

Hypothesis 1: Core self evaluations will be positively related to student satisfaction.

Hypothesis 2: Core self evaluations will be positively related to life satisfaction among students.

Hypothesis 3: Core self evaluations will be positively related to academic performance.

These hypotheses stem directly from the Judge et al. (2003) study of the CSES.

\section{METHOD}

\section{Participants}

One hundred and ninety-nine freshman students, 118 female, 81 male, completed self-report measures of interest. Ages ranged from 18-66 years, with the median age being 19.

\section{Procedure}

Students were given packets of questionnaires which they returned over a one week period three quarters into the first semester. Participation was voluntary.

\section{Measures}

Core Self Evaluations. Core self evaluations were measured with the Core Self-Evaluation Scale (CSES) developed by Judge et al. (2003). This 12 item measure measures the four components of self-esteem, self-efficacy, neuroticism, and locus of control. Students responded to the items on a 5 point Likert scale ranging from strongly agree to strongly disagree.

Student satisfaction. Student satisfaction was measured with a six item student satisfaction scale developed by Broucek (2003). Five items were adapted from Judge, Bono, \& Locke (2000) who adapted them from the BrayfieldRothe (1951) scale. The items were modified to reflect a student rather than work situation, e.g. "I feel fairly satisfied being a student" was used rather than "I feel fairly satisfied with my present job". Students responded to the items on a 5 point Likert scale ranging from strongly agree to strongly disagree. Cronbach's alpha for this scale was .84. A sample item is: "I feel satisfied being a student". Students responded to the items on a 5 point Likert scale ranging from strongly agree to strongly disagree. 
As well, student satisfaction was measured with a 28-item variant of the College Student Satisfaction Questionnaire (CSSQ) developed by Beltyukova and Fox (2002) as an universal metric of student satisfaction. Using a 5-point Likert-type scale, students rate each item from (1) very dissatisfied to (5) very satisfied. Items range from academic advising to student housing to extracurricular activities. Ratings on each item were added to yield an overall satisfaction score.

Life Satisfaction. Life satisfaction was measured with the five item Satisfaction with Life Scale (Diener, Emmons, Larsen \& Griffin, 1985). Students responded to the items on a 5 point Likert scale ranging from strongly agree to strongly disagree.

Academic Performance. Performance was measured by the actual, cumulative first-semester GPA of the respondents.

\section{RESULTS}

Intercorrelations for the students' scores on the CSES, Student Satisfaction scale, College Student Satisfaction Questionnaire, Satisfaction with Life Scale, and first semester cumulative GPA are presented in Table 1. Consistent with hypotheses, the CSES was significantly positively correlated with both student satisfaction measures, life satisfaction, and GPA.

\section{Table 1 Correlation Matrix}

1. CSES

2. STU SATISFACTION

3. CSSQ

4. LIFE SATISFACTION

5. GPA

$\begin{array}{lllll}1 & 2 & 3 & 4 & 5 \\ -- & 40^{* *} & 45^{* *} & 53^{* *} & 28^{* *} \\ & -- & 57^{* *} & 37^{* *} & 20^{* *} \\ & & -- & 50^{* *} & 25^{* *} \\ & & & -- & 23^{* *} \\ & & & & --\end{array}$

$\mathrm{p}<.05, * * \mathrm{p}<.01, * * * \mathrm{p} .001$. Decimal Points omitted.

Also noted is the fact that the mean CSES with the student population was 3.33. This is markedly lower than the mean CSES scores reported in Judge, et al.'s (2003) samples which ranged from 3.78 to 4.03. The correlations with both measures of student satisfaction, life satisfaction, and academic performance were similar to the values found by Judge et al., (2003), however. The values in that study were .41-49 for job satisfaction, .45-. 54 for life satisfaction, and .23-.24 for job performance.

\section{DISCUSSION}

The results of this study suggest that the relationship between core self evaluations and job satisfaction, life satisfaction, and work performance can be successfully extended to student satisfaction and academic performance. Correlations between core self evaluations in students reached the same order of magnitude with regard to satisfaction and performance as the correlations between CSE's in an adult sample.

That CSE's are significantly correlated with GPA suggests that this measure may be appropriate to use when dealing with freshman populations. Low scorers on the CSES are obvious candidates for enhanced freshman orientation/student success courses. 


\section{BIBLIOGRAPHY}

1. Brayfield, A.H. \& Rothe, H.F. (1951). "An index of job satisfaction”. Journal of Applied Psychology, 35, 307-311.

2. Broucek, W. (2003). "An examination of organizational citizenship behavior in an academic setting from the perspective of the five factor model", International Business and Economics Research Journal, 2, 6369.

3. Costa, P.T. \& McCrae, R.R. (1992). NEO-PI-R Professional manual. Odessa, FL: Psychological Assessment Resources Inc.

4. Diener, E, Emmons, R.A., Larsen, R.J., \& Griffin, S. (1985). "The Satisfaction with Life Scale”. Journal of Personality Assessment, 49, 71-75

5. Erez, A. \& Judge, T.A. (2001). "Relationship of core self-evaluations to goal setting, motivation, and performance". Journal of Applied Psychology, 86, 1270-1279.

6. Harter, S. (1990). "Causes, correlates, and the functional role of global self-worth: A life-span perspective". In R.J. Sternberg \& J. Kolligan, Jr. (Eds.) Competence considered (pp.67-97). New Haven, CT: Yale University Press.

7. Judge, T. A. \& Bono, J.E. (2001a). “A rose by any other name... Are self-esteem, generalized self-efficacy, Neuroticism, and locus of control indicators of a common construct?" In Roberts, B.B. \& Hogan, R. (eds.) Personality psychology in the workplace (pp.93-118)/ Washington, DC: American Psychological Association.

8. Judge, T. A. \& Bono, J.E. (2001b). "Relationship of core self evaluations traits - self-esteem, generalized self-efficacy, locus of control, and Emotional Stability - with job satisfaction and job performance: A metaanalysis", Journal of Applied Psychology, 86, 80-92.

9. Judge, T. A. , Bono, J.E., \& Locke, E.A. (2000). "Personality and job satisfaction: The mediating role of job characteristics", Journal of Applied Psychology, 85, 237-249.

10. Judge, T. A., Erez, A., \& Bono, J.E. (1998). "The power of being positive: The relationship between positive self-concept and job performance", Human Performance, 11,167-187.

11. Judge, T. A., Erez, A., Bono, J.E., \& Thoresen, C.J. (2003). "The Core Self-Evaluations Scale: Development of a measure", Personnel Psychology, 56, 303-331.

12. Judge, T. A., Locke, E.A., \& Durham, C.C. (1997). "The dispositional causes of job satisfaction: A core evaluations approach", Research in Organizational Behavior, 19, 151-188.

13. Judge, T. A., Locke, E.A., Durham, C.C., \& Kluger, A.N. (1998). "Dispositional effects on job and life satisfaction: The role of core evaluations", Journal of Applied Psychology, 83, 17-34.

14. Locke, E.A., McClear, K., \& Knight, D. (1996) "Self-esteem and work", International Review of Industrial/Organizational Psychology, 11, 1-32.

15. Rotter, J.B. (1966). "Generalized expectancies for internal versus external control of reinforcement", Psychological Monographs, 80,(1, Whole No. 609. 